\title{
The role of detoxifying enzymes in the resistance of the cowpea aphid (Aphis craccivora Koch) to thiamethoxam
}

\author{
Ibrahim Saleh Abdallah'*, Hala Mohamed Abou-Yousef², Eman Atef Fouad², \\ Mohammed Abd El-Hady Kandil ${ }^{1}$
}

${ }^{1}$ Department of Economic Entomology and Pesticides, Faculty of Agriculture, Cairo University, 12613 Giza, Egypt

${ }^{2}$ Department of Bioassay, Central Pesticides Laboratory, Agriculture Research Center, 12618 Giza, Egypt

Received: July 24, 2015

Accepted: February 15, 2016

\begin{abstract}
The cowpea aphid (Aphis craccivora Koch) is considered a serious insect pest attacking several crops. We carried out biochemical studies to elucidate the role of the metabolising enzymes in conferring resistance to thiamethoxam, in two strains (resistant and susceptible) of the cowpea aphid. Bioassay experiments showed that the thiamethoxam selected strain developed a 48 fold resistance after consecutive selection with thiamethoxam for 12 generations. This resistant strain also exhibited cross-resistance to the tested carbamates; pirimicarb and carbosulfan, organophosphorus (malathion, fenitrothion, and chlorpyrifos-methyl), and the neonicotinoid (acetamiprid). Synergism studies have indicated that S,S,S-tributyl phosphorotrithioate (DEF), a known inhibitor for esterases, increased thiamethoxam toxicity 5.58 times in the resistant strain compared with the susceptible strain. Moreover, the biochemical determination revealed that carboxylestersae activity was 30 times greater in the resistant strain than in the susceptible strain. In addition, the enzyme activity of glutathione S-transferase (GST) and mixed function oxidases (mfo) increased only in the resistant strain 3.7 and 2.7 times, respectively, in relation to the susceptible (the control). Generally, our results suggest that the higher activity of the detoxifying enzymes, particularly carboxylesterase, in the resistant strain of the cowpea aphid, apparently have a significant role in endowing resistance to thiamethoxam, although additional mechanisms may contribute.
\end{abstract}

Key words: Aphis craccivora, detoxifying enzymes, resistance, synergism, thiamethoxam

\section{Introduction}

Throughout the world, the cowpea aphid (Aphis craccivora Koch) is considered to be a serious insect pest to a variety of crops (Blackman and Eastop 2000; Al-Eryan and El-Tabbakh 2004; Kuo et al. 2006). Aphids cause significant economic damage either directly; by sucking sap from leaves, pods, and other aerial tissues, or indirectly; through transmission of major viruses like the faba bean necrotic yellows virus (FBNYV), and the bean leaf roll virus (BLRV) (Laamari et al. 2008).

The control of $A$. craccivora relies almost exclusively on the use of chemical insecticides. Most insecticide groups used for managing aphids are organophosphates, carbamates, pyrethroids, and neonicotinoids (Shetlar 2001; Tang et al. 2013). Due to the intensive and repeated use of the same insecticides or insecticides with similar modes of action, resistance developed towards these insecticides.

Almost 20 aphid species have developed at least one known insecticide resistance mechanism (Simon 2008; Van Emden and Harrington 2007). Thiamethoxam is a second-generation neonicotinoid and it belongs to the thianicotinyl subclass. In Egypt, under the trade name Actara, thiamethoxam provides excellent control of a broad range of economically important insects, such as aphids, whiteflies, thrips, rice hoppers, Colorado potato beetle, flea beetles, wireworms, leaf miners as well as some lepidopterous species. In Egypt, thiamethoxam is the second biggest neonicotinoid, as far as sales are concerned (Mohamed et al. 2015).

The extensive use of neonicotinoids particularly thiamethoxam in insect control, and the lower availability of aphicides with dissimilar modes of action to rotate with the neonicotinoids, resulted in the development of resistance in aphids (Srigiriraju 2008). Pan et al. 2015 reported that a thiamethoxam-resistant strain of Aphis gossypii Glover displayed a 19.35 fold greater resistance to thiamethoxam compared to the susceptible strain. Three major groups of detoxifying enzymes have been shown to play a significant role in specific cases of insecticide resistance; cytochrome P450 monooxygenases, esterases, and glutathione transferases (Taniai et al. 2003). Therefore, the main objective of this study was to clarify the role of the aforementioned insect metabolising enzymes in the resistance to thiamethoxam in the cowpea aphid. In addition, the screening of potential cross-resistance to other insecticides belonging to three chemical classes, was also examined. 


\section{Materials and Methods}

\section{Chemicals and the tested insecticide}

Piperonyl butoxide (PBO), S,S,S-tributyl phosphorotrithioate (DEF), glutathione (GSH), p-nitroanisole (p-NA), 1-chloro-2,4-dinitrobenzene (CDNB), and acetylthiocholine iodide (ATChI), were obtained from Sigma-Aldrich. Roth supplied 5,5-dithio-bis (2-nitrobenzoic acid) (DTNB). Diethyl maleate (DEM) was obtained from AlfaAesar, reduced nicotinamide adenine dinucleotide phosphate (NADPH) from Sorachim, and $\alpha$-naphthyl acetate ( $\alpha$-NA) was obtained from MPBio. All chemicals were technical grade (99\%). The insecticide commercial formulation of thiamethoxam (Actara 25\%WG) was obtained from Syngenta (Syngenta Agro Egypt).

\section{Test insect}

Two strains of the cowpea aphid were used for this study: one strain is the thiamethoxam laboratory susceptible (S) strain obtained in June 2007, from the Plant Protection Research Institute, Egypt. The other strain is the thiamethoxam resistant $(\mathrm{R})$ strain. This strain was originally collected from faba bean fields in the Sharkia Governorate, Egypt. This strain was continuously selected for 12 generations during which concentrations of thiamethoxam killed $50-60 \%$ of the aphids. Both S and R strains were reared on seedling of faba bean plants in the laboratory and kept at $20-23^{\circ} \mathrm{C}, 60 \%$ relative humidity $(\mathrm{RH})$, and $16: 8$ (L: D) h photoperiod.

\section{Aphid bioassay and cross-resistance studies}

To evaluate the activity of thiamethoxam on the cowpea aphid, the leaf dipping method described by Moores et al. (1996) was used. The series of thiamethoxam concentrations were freshly prepared. Then, fresh faba bean leaves were dipped into thiamethoxam aqueous solutions for $10 \mathrm{~s}$, air-dried, and placed upside down on an agar bed in labeled Petri dishes ( $60 \mathrm{~mm}$ in diameter). Ten $A$. craccivora apterous adults were placed on the surface of a treated leaf. Leaves dipped in water only, served as the controls. Five replicate patches of aphids were used. The mortality was assessed after $24 \mathrm{~h}$ and the mortality was corrected with the use of Abbott's formula (Abbott 1925) Probit analysis using Ldp-line software was used to calculate $\mathrm{LC}_{50}$ values. The resistance ratio (RR) was calculated at the $\mathrm{LC}_{50}$ level as: $\mathrm{RR}=\mathrm{LC}_{50}$ of $\mathrm{R}$ strain/ $\mathrm{LC}_{50}$ of $\mathrm{S}$ strain. The cross-resistance of the thiamethoxam resistant strain was examined against six other different insecticides belonging to three chemical groups including, carbamates, organophosphates, and neonicotinoids, as shown in table 1.

\section{Synergism studies}

To investigate the potential involvement of detoxifying enzymes endowing aphids a resistance to thiamethoxam, the following synergists were used: DEF as the esterase inhibitor, DEM as the GST inhibitor, and PBO as the cytochrome P450 oxidases inhibitor. The maximum dose of synergist $\left(10 \mathrm{mg} \cdot \mathrm{l}^{-1}\right)$ that showed zero mortality in the susceptible strain was used in this study. Combined mixtures of each synergist with thiamethoxam were added to make the solution. Faba bean leaves were dipped into this solution for $10 \mathrm{~s}$, and then 10 A. craccivora apterous adults were placed on the leaf treated with synergist + thiamethoxam mixture, and kept in the rearing chamber until mortality was recorded, as mentioned in the bioassay experiment.

\section{Statistical analysis}

Data were statistically analysed with the Student's t-test using SPSS software to determine the difference between the mean values of the resistant strain and the control (laboratory) susceptible strain. The values were expressed as the mean + the standard error.

\section{Biochemical assay}

Mixed function oxidases activity

Mixed function oxidases (mfo) activity was analysed according to Hansen and Hodgson (1971). Ten adult aphids from each strain were homogenised in $500 \mu$ l of ice-cold $0.1 \mathrm{M}$ phosphate buffer ( $\mathrm{pH}$ 7.8). Homogenates were centrifuged at $15,000 \mathrm{~g}$ for $15 \mathrm{~min}$ at $4^{\circ} \mathrm{C}$ and the supernatants were transferred to new tubes. An addition of $100 \mu \mathrm{l}$ of $2 \mathrm{mM}$ p-nitroanisole solution and $90 \mu \mathrm{l}$ enzyme stock solutions were put in each well of a microplate and mixed. After incubation for $2 \mathrm{~min}$ at $27^{\circ} \mathrm{C}$, the reaction was initiated by the addition of $10 \mu \mathrm{l}$ of $9.6 \mathrm{mM}$ NADPH. The optical density at $405 \mathrm{~nm}$ was immediately recorded at intervals of $25 \mathrm{~s}$ for $10 \mathrm{~min}$ using the molecular device: $\mathrm{V}_{\max }$ kinetic microplate reader.

Table 1. Development of thiamethoxam resistance in the cowpea aphid laboratory strain, selected for 12 generations

\begin{tabular}{lccc}
\hline \multicolumn{1}{c}{ Generation } & $\mathrm{LC}_{50}\left[\mathrm{mg} \cdot \mathrm{l}^{-1}\right]$ & Slope \pm SE & $\mathrm{RR}($ fold $)$ \\
\hline Susceptible strain & $0.079(0.034-0.134)$ & $1.469 \pm 0.149$ & - \\
Parent strain & $0.142(0.109-0.187)$ & $0.928 \pm 0.083$ & 1.797 \\
2nd generation & $0.146(0.114-0.188)$ & $0.926 \pm 0.083$ & 1.848 \\
4th generation & $0.420(0.361-0.563)$ & $0.982 \pm 0.072$ & 1.316 \\
8th generation & $1.211(0.995-1.494)$ & $1.375 \pm 0.147$ & 3.32 \\
10th generation & $3.029(2.477-3.942)$ & $1.58 \pm 0.208$ & 38.34 \\
12th generation & $3.793(2.87-5.104)$ & $1.08 \pm 0.194$ & 48.01 \\
\hline
\end{tabular}

$\mathrm{RR}$ (resistance ratio) $=\mathrm{LC}_{50}$ of selected resistant strain/LC $\mathrm{L}_{50}$ of susceptible laboratory strain 
Table 2. Cross-resistance of thiamethoxam resistant and susceptible strains of the cowpea aphid, to various tested insecticides

\begin{tabular}{lccc}
\hline \multirow{2}{*}{ Insecticide } & \multicolumn{2}{c}{$\mathrm{LC}_{50}\left[\mathrm{mg} \cdot \mathrm{l}^{-1}\right]$} & $\mathrm{RR}$ \\
\cline { 2 - 4 } Carbamate & \multicolumn{2}{c}{ Susceptible strain } & \\
\hline Pirimicarb & $0.027(0.025-0.038)$ & $0.3(0.209-0.388)$ & 11.2 \\
Carbosulfan & $0.17(0.116-0.247)$ & $2.007(1.051-3.564)$ & 11.0 \\
\hline Neonicotinoid & & $3.134(2.453-3.926)$ & 8.5 \\
\hline Acetamiprid & $0.369(0.251-0.618)$ & & 5.0 \\
\hline OPs & & $2.105(1.633-2.754)$ & 8.72 \\
\hline Fenitrothion & $0.418(0.318-0.593)$ & $1.99(0.806-4.277)$ & 4.0 \\
Malathion & $0.228(0.146-0.349)$ & $0.2246(0.181-0.276)$ & \\
Chlorpyrifos-methyl & $0.059(0.021-0.127)$ & & \\
\hline
\end{tabular}

$\mathrm{RR}$ (resistance ratio) $=\mathrm{LC}_{50}$ of selected resistant strain/LC $\mathrm{L}_{50}$ of susceptible laboratory strain

\section{Total esterase activity}

Esterase activity was assayed with $\alpha$-NA as the substrate, according to Van Asperen (1962) with the modification of Cao et al. (2008). Fifty adults from each strain were homogenised in $500 \mu \mathrm{l}$ of ice-cold phosphate buffer $(0.1 \mathrm{M}$, $\mathrm{pH}$ 7.0). The homogenates were centrifuged at $12,000 \mathrm{~g}$ for $15 \mathrm{~min}$ at $4^{\circ} \mathrm{C}$ and the supernatants were transferred to new tubes. Fifty $\mu$ l of enzyme solution was incubated with $50 \mu \mathrm{l} \alpha$-NA $\left(30 \mathrm{mM}\right.$ ) for $15 \mathrm{~min}$ at $30^{\circ} \mathrm{C}$. The reaction was stopped by adding $50 \mu \mathrm{l}$ of stop solution (two parts of $1 \%$ Fast Blue RR and five parts of $5 \%$ sodium dodecyl sulfate). The absorbance was measured at $600 \mathrm{~nm}$ for the hydrolysis of $\alpha$-NA at UV/Vis spectrophotometer (V-530). The mean levels of total esterase activity cited, were based on protein content and $\alpha$-naphthol standard curves.

\section{Glutathione S-transferase activity (GST)}

GST activity was assayed as described by Habing et al. (1974). Ten adults from each strain were homogenised in $200 \mu \mathrm{l}$ of ice-cold phosphate buffer (0.1 M, pH 6.5). The homogenates were centrifuged at $12,000 \mathrm{~g}$ for $15 \mathrm{~min}$ at $4^{\circ} \mathrm{C}$ and the supernatants were transferred to new tubes. The reaction solution contained $100 \mu \mathrm{l}$ of supernatant, $10 \mu \mathrm{l}$ of CDNB $(30 \mathrm{mM})$, and $10 \mu \mathrm{l}$ of GSH (50 mM). Enzyme activity was determined by using a UV/Vis spectrophotometer (V-530) to continuously monitor the change in absorbance at $430 \mathrm{~nm}$ for three min at $25^{\circ} \mathrm{C}$.

\section{Acetylcholinesterase (AChE) activity}

AChE activity was measured according to Ellman et al. (1961) with some modifications that allowed the use of a kinetic assay with a molecular devices: the $\mathrm{V}_{\max }$ kinetic microplate reader. Twenty-five adult aphids from the $S$ and R strains were homogenised in $200 \mu \mathrm{l}$ of ice-cold $0.1 \mathrm{M}$ phosphate buffer ( $\mathrm{pH} 7.5)$ containing $0.1 \%(\mathrm{~V} / \mathrm{V})$ Triton X-100. Homogenates were centrifuged at 13,000 g for $15 \mathrm{~min}$ at $4^{\circ} \mathrm{C}$ and the supernatants were transferred to new tubes. Twenty five $\mu \mathrm{l}$ of the supernatant was placed in a microplate well, $2 \mu \mathrm{l}$ of $0.075 \mathrm{M}$ ATChI, $8 \mu \mathrm{l}$ of $0.01 \mathrm{M}$ DTNB and potassium phosphate buffer $(0.1 \mathrm{M}$,
$\mathrm{pH} 7.5)$ up to $200 \mu \mathrm{l}$. The reaction was started by the addition of the substrate (ATChI) and the reagent (DTNB), the change in absorbance at $405 \mathrm{~nm}$ was recorded for $20 \mathrm{~min}$. Protein content was determined by the method of Bradford (1976), using bovine serum albumin as the standard.

\section{Results}

The results presented in table 2 showed the changes in A. craccivora adults' response to the continuous selection with thiamethoxam for 12 generations. Toxicity regression lines were established and the $\mathrm{LC}_{50}$ and slope values for the resistant strain in each generation were determined.

A little increase of the RR was observed. The resistance ratio was elevated slightly from 1.79 fold in the parent strain to 5.32 fold after selection for four generations. Thiamethoxam resistance rapidly increased after the 8th generation from 15.32 fold to 38.34 fold. The resistance ratio gradually increased to reach 48 fold after 12 generations. The slope of the regression line in the laboratory strain was 1.46 .

The cross-resistance of the thiamethoxam resistant strain of $A$. craccivora against six various insecticides belong to three different groups, is summarised in table 3. This resistant strain exhibited cross resistance to the tested carbamate; pirimicarb and carbosulfan as the resistance rations were 11.2 and 11 fold, respectively. While the strain showed high resistance (8.72 fold) to organophosphate; malathion and lower resistance to fenitrothion and chlorpyrifos-methyl (5 and 4 fold, respectively). With regard to the neonicotinoid insecticide acetamiprid, the resistance level obtained was 8.5 fold.

\section{Synergism study}

The synergists PBO, DEM and DEF are normally considered as known inhibitors of mfo, GST and esterases, respectively. Data in table 4 pointed out that DEF, PBO and DEM effectively increased thiamethoxam toxicity in the resistant strain as the ratios of the synergism were 5.58, 2.09 and 2.18 as a result of inhibition of esterases, $\mathrm{mfo}$ and GST, respectively. 
Table 3. Toxicity of thiamethoxam alone and in combination with three synergists against susceptible (S) and resistant (R) strains of the cowpea aphid

\begin{tabular}{|c|c|c|c|c|}
\hline Strain & Treatment & Slope $\pm S E$ & $\mathrm{LC}_{50}\left[\mathrm{mg} \cdot \mathrm{1}^{-1}\right]$ & SR ratio \\
\hline \multirow{4}{*}{$S$} & thiomethoxam & $1.664 \pm 0.154$ & $0.189(0.158-0.223)$ & - \\
\hline & thiomethoxam + DEF & $1.08 \pm 0.139$ & $0.164(0.128-0.216)$ & 1.15 \\
\hline & thiomethoxam + PBO & $1.722 \pm 0.243$ & $0.207(0.174-0.243)$ & 0.91 \\
\hline & thiomethoxam + DEM & $1.789 \pm 0.205$ & $0.148(0.124-0.176)$ & 1.27 \\
\hline \multirow{4}{*}{$\mathrm{R}$} & thiomethoxam & $2.134 \pm 0.218$ & $3.701(3.195-4.297)$ & - \\
\hline & thiomethoxam + DEF & $1.115 \pm 0.192$ & $0.663(0.479-0.86)$ & 5.58 \\
\hline & thiomethoxam + PBO & $0.941 \pm 0.192$ & $1.765(1.263-2.463)$ & 2.09 \\
\hline & thiomethoxam + DEM & $1.838 \pm 0.223$ & $1.694(1.368-2.055)$ & 2.18 \\
\hline
\end{tabular}

$\mathrm{SR}$ (synergistic ratio) $=\mathrm{LC}_{50}$ of insecticide alone $/ \mathrm{LC}_{50}$ of insecticide + synergist

Table 4. Detoxification enzyme activity in the thiamethoxam susceptible (S) and resistant (R) strains of the cowpea aphid

\begin{tabular}{lccc}
\hline \multicolumn{1}{c}{ Enzyme } & \multicolumn{2}{c}{ Enzyme activity } & \multirow{2}{*}{ Activity ratio } \\
\cline { 2 - 4 } & S strain & R strain & 30.00 \\
\hline $\begin{array}{l}\text { Carboxylesterase } \\
{\left[\mathrm{mol} \cdot \mathrm{min}^{-1} \cdot \mathrm{mg}^{-1} \text { protein }\right]}\end{array}$ & $0.006 \pm 0.001$ & $0.180 \pm 0.018^{* *}$ & 3.72 \\
\hline $\begin{array}{l}\text { Glutathione-S-transferase } \\
{\left[\mu \mathrm{mol} \cdot \mathrm{min}^{-1} \cdot \mathrm{mg}^{-1} \text { protein] }\right.}\end{array}$ & $7.24 \pm 0.50$ & $24 \pm 0.94^{* *}$ & 2.70 \\
\hline $\begin{array}{l}\text { Mixed function oxidase } \\
{\left[\mathrm{mOD} \cdot \mathrm{min}^{-1} \cdot \mathrm{mg}^{-1} \text { protein }\right]}\end{array}$ & $2.39 \pm 0.18$ & $6.48 \pm 1.43^{*}$ & \multirow{2}{*}{} \\
\hline
\end{tabular}

Enzyme activity is expressed as the mean $\pm \mathrm{SE}$.

The means followed by * in the same line are significantly different; ** significantly different at $\mathrm{p}=0.01$

Table 5. Activity of acetylocholinesterase (AChE) in the thiamethoxam susceptible (S) and resistant (R) strains of the cowpea aphid

\begin{tabular}{ccc}
\hline Strain & Specific activity $\left[\mathrm{mOD} \cdot \mathrm{min}^{-1} \cdot \mathrm{mg}^{-1}\right]$ & Activity ratio \\
\hline $\mathrm{S}$ & $10.18 \pm 1.18$ & 1 \\
$\mathrm{R}$ & $37.55 \pm 1.18^{* *}$ & 3.68 \\
\hline
\end{tabular}

Specific activity of three replicates (expressed as the means \pm SE) followed by ${ }^{* *}$ are significantly different at $p=0.01$

Table 6. Activity of acetylocholinesterase (AChE) in the thiamethoxam susceptible (S) and resistant (R) strains of cowpea aphid

\begin{tabular}{ccc}
\hline Strain & Specific activity $\left[\mathrm{mOD} \mathrm{min}^{-1} \cdot \mathrm{mg}^{-1}\right]$ & Activity ratio \\
\hline $\mathrm{S}$ & $10.18 \pm 1.18$ & 1 \\
$\mathrm{R}$ & $37.55 \pm 1.18^{*}$ & 3.68 \\
\hline
\end{tabular}

Specific activity of three replicates (expressed as means \pm SE) followed by * are very significantly different at $\mathrm{p}=0.01$

\section{Activity of detoxifying enzymes}

This experiment pointed out the potential role of thiamethoxam metabolism in conferring resistance in the $R$ strain. Data set up in table 5 indicated that the activity of all determined detoxifying enzymes; carboxylesterase (CarE), GST and mfo was significantly higher in the R than that in the $S$ strain. The activity of CarE was much greater in the $\mathrm{R}$ strain related to the $\mathrm{S}$ strain as the activity ratio was 29 fold. However, the activity of GST increased to some extent to 3.7 fold and the lowest determined activity was observed for the detoxifying enzyme mfo.

\section{AChE activity}

The activity of AChE in both strains of A craccivora is shown in table 6 . The resistant strain exhibited significantly higher AChE activity (3.68 fold) compared to the susceptible strain $(p<0.05)$.

\section{Discussion}

The results of the resistance to thiamethoxam in A. craccivora revealed that the susceptible strain was highly sensitive to thiamethoxam compared with the resistant se- 
lected strain. It is interesting to observe that selection for 12 continuous generations elevated the resistance level to almost 48 fold. This might be because the factors (gene/s) of the resistance could have existed in the field strain of A. craccivora before selection.

Pan et al. (2015) reported that thiamethoxam-resistant strain of the cowpea aphid exhibited 19.35 fold greater resistance to thiamethoxam than that in the susceptible strain.

Cross-resistance results indicated thiamethoxam resistance in the cowpea aphid. Six other insecticides dissimilar to thiamethoxam's mode of action also indicated resistance in the cowpea aphid. These insecticides were: organophosphates (malathion, chlorpyrifos methyl, and fenitrothion) and carbamates (primicarb, and carbosulfan). Cross-resistance was also observed to the neonicotinoid insecticide (acetamiprid) that shares the same target site. A colony of Bemisia tabaci resistant to acetamiprid also showed a high cross-resistance to thiamethoxam (Horowitz et al. 2004), and these findings were similar to those in our study. In addition, Koo et al. (2014) stated that the imidacloprid (neonicotinoid) resistant strain of A. gossypii showed a cross resistance to acetamiprid and thiacloprid.

In contrast to the present data, the thiamethoxam resistant strain (100 fold) of B. tabaci showed no cross-resistance to acetamiprid and imidacloprid, while another colony which had a 500 fold resistance to thiamethoxam showed a slight cross-resistance to the other neonicotinoids (4 fold) (Ishaaya et al. 2005).

The results of the biochemical assay showed that the thiamethoxam resistant strain of $A$. craccivora is likely have high significant carboxylesterase activity as a remarkable synergism to thiamethoxam was obtained when DEF was added (toxicity increased 5.5 times). These data were confirmed by the determination of the activity of carboxylesterase that was 30 times more active in the $\mathrm{R}$ than that in the $\mathrm{S}$ strain. Kandil et al. (2008) suggested that esterases may have a role in the detoxification mechanism observed in the thiamethoxam B. tabaci resistant strain using the known thiamethoxam synergist; DEF. Moreover, the toxicity of organophosphate insecticides toward the tobacco aphid resistant strains was increased using the esterase inhibitor; DEF. This increase suggests that the mechanism of resistance was due to increased ester hydrolysis caused by higher levels of carboxylesterase (Harlow and Lampert 1990). Pan et al. (2015) concluded that expression levels of esterase were upregulated significantly in the resistant strain compared to the susceptible strain of the cotton aphid. In the United States, resistant populations of the tobacco aphid had approximately 2.5 times greater carboxylesterase activity than the susceptible strain (Harlow and Lampert 1990). One of the resistance mechanisms described in green peach aphid was the enhanced production of carboxylesterases that confer broad spectrum resistance to members of the organophosphates, mono-methyl carbamates and, to a much lesser extent, to the pyrethroids (Foster et al. 2003). On the other hand, GST and mfo apparently had little role in conferring resistance in the selected thiamethoxam resistant strain (Table 4). This result agrees with that of Koo et al. (2014) who noted that no effect of mfo in the imidacloprid resistant strains of $A$. gossypii was found when using either synergists or a determination of the enzyme activity. Although GSTs play an important role in resistance occurrence against several classes of insecticides including organophosphates (Syvanen et al. 1996; Wei et al. 2001; Abel et al. 2004), no significant differences in GST activities were found in the imidacloprid resistant strain of $A$. gossypii compared to the sensitive one as reported by Koo et al. (2014).

In this study we determined AChE for the purpose of examining the response of this enzyme in the $\mathrm{R}$ strain although there is no correlation between AChE and neonicotinoid toxicity. However, interestingly the AChE activity in the R strain increased significantly as compared to the $\mathrm{S}$ strain. This finding agrees with Samson-Robert et al. (2014) who stated that with the rare exception of one pyrethroid (deltamethrin), the neonicotinoid compounds are the only agrochemicals that cause an increase in AChE activity. In addition, increased AChE activity has also been reported in response to exposure to neonicotinoids, in both honey bees and other arthropods (Morakchi et al. 2005; Boily et al. 2013).

In general, from the present work it can be concluded, that the developed resistance to thiamethoxam in the resistant strain of A. craccivora could be due to enhanced activity of the detoxifying enzymes namely the carboxyesterases. In addition to the improved activity of CarE, the increased AChE activity in the R strain might also elucidate the observed cross resistance against tested carbamate and organophosphate insecticides.

Our study suggests that to attain effective and sustainable aphid management, it is prudent to use all the available effective aphicide groups. Approaches based on the rotation of new mode of action groups have the potential to lessen the intensity of selection for new resistance mechanisms. Also, different control strategies can be integrated into practical aphid management programs. It is recommended, that resistance management guidelines should be adopted and monitoring implemented so as detect any possible alteration in aphid susceptibility that may lead to the occurrence of new resistance cases.

\section{References}

Abbott W.S. 1925. A method for computing the effectiveness of an insecticide. Journal of Economic Entomology 18 (2): 265-267.

Abel E.L., Bammler T.K., Eaton D.L. 2004. Biotransformation of methyl parathion by glutathione S-transferases. Toxicological Sciences 79 (2): 224-232.

AL-Eryan M.A.S., El-Tabbakh S.S. 2004. Forecasting yield of corn, Zea mays infested with corn leaf aphid, Rhopalosiphum maidis. Journal of Applied Entomology 128 (4): 312-315.

Blackman R.L., Eastop V.F. 2000. Aphids on the World's Crops. An Identification and Information Guide. 2nd ed. John Wiley and Sons Ltd., Chichester, UK, 476 pp.

Boily M., Sarrasin B., DeBlois C., Aras P., Chagnon M. 2013. Acetylcholinesterase in honey bees (Apis mellifera) exposed to neonicotinoids, atrazine and glyphosate: laboratory and 
field experiments. Environmental Science and Pollution Research. DOI: 10.1007/s11356-013-1568-2.

Bradford M.M. 1976. A rapid and sensitive method for the quantitation of microgram quantities of protein utilizing the principle of protein-dye binding. Analytical Biochemistry 72 (1-2): 248-254.

Cao C., Zhang J., Gao X., Liang P., Guo H. 2008. Overexpression of carboxylesterase gene associated with organophosphorus insecticide resistance in cotton aphids, Aphis gossypii (Glover). Pesticide Biochemistry and Physiology 90 (3): 175-180.

Ellman G.L., Courtney K.D., Andres V., Featherstone R.M. 1961. A new and rapid colorimetric determination of acetylcholinesterase activity. Biochemical Pharmacology 7 (2): 88-95.

Foster S.P., Denholm I., Thompson R. 2003. Variation in response to neonicotinoid insecticides in peach-potato aphids, $\mathrm{My}$ zus persicae (Homoptera: Aphididae). Pest Management Science 59 (2): 166-173.

Habing W.H., Pabst J., Jackoby W.B. 1974. Glutathione S-transferases. The first enzymatic step in mercapturic acid formation. The Journal of Biological Chemistry 249 (22): 7130-7139.

Hansen L.G., Hodgson E. 1971. Biochemical characteristics of insect microsomes. N- and O-demethylation. Biochemical Pharmacology 20 (7): 1569-1578.

Harlow C.D., Lampert E.P. 1990. Resistance mechanisms in two color forms of the tobacco aphid (Homoptera: Aphididae). Journal of Economic Entomology 83: 2130-2135

Horowitz A.R., Kontsedalov S., Ishaaya I. 2004. Dynamic of resistance to the neonicotinoids, acetamiprid and thiamethoxam, in Bemisia tabaci (Homoptera: Aleyrodidae). Journal of Economic Entomology 97 (6): 2051-2056.

Ishaaya I., Kontsedalov S., Horowitz A.R. 2005. biorational insecticides: mechanism and cross-resistance. Archives of Insect Biochemistry and Physiology 58 (4): 192-199.

Kandil M.A., Saleh A.Y., El Dieb W.H., Farghaly S.F. 2008. Resistance mechanisms of whitefly Bemisia tabaci (Homoptera: Aleyrodidae) to thiamethoxam and profenofos. Asian Journal of Biological Sciences 1: 33-38.

Koo H., An J., Park S., Kim J., Kim G. 2014. Regional susceptibilities to 12 insecticides of melon and cotton aphid Aphis gossypii (Hemipetra: Aphididae) and point mutation associated with imidacloprid resistance. Crop Protection 55: 91-97.

Kuo M.H., Chiu M.C., Perng J.J. 2006. Temperature effects on life history traits of the corn leaf aphid, Rhopalosiphum maidis (Homoptera: Aphididae) on corn in Taiwan. Applied Entomology and Zoology 41: 171-177.

Laamari M., Khelfa L., Coeur d'Acier A. 2008. Resistance source to cowpea aphid (Aphis craccivora Koch) in broad bean (Vicia faba L.) Algerian landrace collection. African Journal of Biotechnology 7 (14): 2486-2490.

Mohamed H.T.G., Mohamed I.A., Abou-Elhagag G.H., Saba R.M. 2015. Toxicity and field persistance of thiametoxam and dinotefuran against cabbage aphid, Brevicoryne brassica L. (Homoptera: Aphididae) under laboratory and field conditions. Journal of Phytopathology and Pest Management 2: 20-26.

Moores G.D., Gao X., Denholm I., Devonshire A.L. 1996. Characterization of insensitive acetylcholinesterase in insecticideresistant cotton aphids, Aphis gossypii Glover (Homoptera: Aphididae). Pesticide Biochemistry and Physiology 56 (2): 102-110.

Morakchi S., Maïza A., Farine P., Aribi N., Soltani N. 2005. Effects of a neonicotinoid insecticide (acetamiprid) on acetylcholinesterase activity and cuticular hydrocarbons profil in German cockroaches. Communications in Agricultural and Applied Biological Sciences 70 (4): 843-848.

Pan Y., Peng T., Gao X., Zhang L., Yang C., Xi J., Xin X., Bi R., Shang Q. 2015. Transcriptomic comparison of thiamethoxam-resistance adaptation in resistant and susceptible strains of Aphis gossypii Glover. Comparative Biochemistry and Physiology 13 (D): 10-15.

Samson-Robert O., Labrie G., Mercier P., Chagnon M., Derome N., Fournier V. 2015. Increased acetylcholinesterase expression in bumble bees during neonicotinoid-coated corn sowing. Scientific Reports 5: 12636. DOI: 10.1038/srep12636

Shetlar D.J. 2001. Aphids on trees and shrubs, HYG-2031-90. Ohio State University Extension Fact Sheet. Department of Horticulture and Crop Science, Ohio State University, USA.

Simon J.Yu. 2008. The Toxicology and Biochemistry of Insecticides. CRC Press, Taylor \& Francis Group, Boca Raton, USA, 211 pp.

Srigiriraju L. 2008. Quantification of insecticide resistance in the tobacco-adapted form of the green peach aphid, $M y$ zus persicae (Sulzer) (Hemiptera: Aphididae). Ph.D. thesis, Virginia Polytechnic Institute and State University, Blacksburg, USA, 220 pp.

Syvanen M., Zhou Z., Wharton J., Goldsbury C., Clark A. 1996. Heterogeneity of the glutathione transferase genes encoding enzymes responsible for insecticide degradation in the housefly. Journal of Molecular Evolution 43 (3): 236-240.

Tang L.D., Jian-Hui W., Shaukat A., Shun-Xiang R. 2013. Establishment of baseline toxicity data to different insecticides for Aphis craccivora Koch and Rhopalosiphum maidis (Fitch) (Homoptera: Aphididae) by glass tube residual film technique. Pakistan Journal of Zoology 45 (2): 411-415.

Taniai K., Inceoglu A.B., Kenji Yukuhiro K., Hammock B.D. 2003. Characterization and cDNA cloning of a clofibrate-inducible microsomal epoxide hydrolase in Drosophila melanogaster. European Journal of Biochemistry 270 (23): 4696-4705.

Van Asperen K. 1962. A study of housefly esterase by means of a sensitive colorimetric method. Journal of Insect Physiology 8 (4): 401-416.

Van Emden H., Harrington R. 2007. Aphids as Crop Pests. CABI North American Office, Cambridge, USA, 699 pp.

Wei S.H., Clark A.G., Syvanen M. 2001. Identification and cloning of a key insecticide-metabolizing glutathione S-transferase (MdGST-6A) from a hyper insecticide-resistant strain of the housefly Musca domestica. Insect Biochemistry and Molecular Biology 31 (12): 1145-1153. 